\title{
Saúde estudantil universitária e as tecnologias virtuais: relato de experiência
}

\author{
University student health and virtual technologies: experience report
}

Salude estudiantil universitaria y tecnologías virtuales: informe de experiencia

Alessandro Costa Silva², Anilce de Araújo Brêtas ${ }^{1 *}$.

\section{RESUMO}

Objetivo: Descrever sobre a percepção emocional dos estudantes diante às tecnologias online, como o uso das salas virtuais. Relato de experiência: $O$ estudo, de cunho qualitativo, adotou como instrumento, no processo investigativo, a coleta de dados por meio de conversas informais dos estudantes referentes ao uso da sala virtual de uma disciplina ministrada em 2011 e em 2020. Foi possível perceber, por meio de seus relatos que: tanto em 2011 quanto em 2020 tiveram dificuldades em conhecer e aprender essas tecnologias, bem como estudar sozinho em frente a um computador o que gerou certo estresse e ansiedade. Esse desconforto, como esperado, foi maior nos estudantes de 2020 proveniente do uso compulsório das salas virtuais em decorrência da COVID-19. Considerações finais: Os estudantes de cursos presenciais, por desconhecerem as salas virtuais, tendem a refutá-las. Por isso, é necessário inserir atividades que busquem a empatia com essas tecnologias para diminuir a ansiedade.

Palavras-chave: Aprendizagem, Estresse e ansiedade, Sala virtual.

\begin{abstract}
Objective: The present article, brought information about students' emotional perception of on line technologies like using virtual classroom. Experience report: The study, adopted as investigative instrument, the collection of data through informal conversations of students regarding the use of the virtual classroom of a discipline taught in 2011 and in 2020. It was possible to perceive through their reports that: both (2011 and 2020) they had difficulties in knowing and learning about these virtual technologies and that a discomfort of the virtual classroom is the isolation of the lack of colleagues for being alone in front of a computer what generated certain stress and anxiety. This discomfort, as expected, was greater in the students of 2020 due to the compulsory use of virtual classrooms due to COVID-19. Final considerations: The face-to-face students, because they are unaware of virtual rooms, tend to refute them. Therefore, it is necessary to insert activities that seek empathy with these technologies to reduce anxiety.
\end{abstract}

Keywords: Learning, Stress and anxiety, Virtual classroom.

\section{RESUMEN}

Objetivo: En el presente artículo se socializó información sobre la percepción emocional de los estudiantes de las tecnologías en línea, como el uso de aulas virtuales. Informe de experiencia: El estudio, de carácter cualitativo, adoptó como instrumento investigativo, la recolección de datos a través de conversaciones informales de los estudiantes sobre el uso de la sala virtual de una disciplina impartida en 2011 y en 2020. Se pudo percibir, a través de su informa que: tanto en 2011 como en 2020 tuvieron dificultades para conocer y aprender sobre estas tecnologías generaron cierto estrés y ansiedad, además de estudiar solos frente a uno ordenador. Esta incomodidad, como era de esperar, fue mayor entre los estudiantes en 2020 debido al uso obligatorio de las aulas virtuales como consecuencia dela COVID-19. Consideraciones finales: Los estudiantes de cursos presenciales, por no conocer las salas virtuales, tienden a refutarlas. Por tanto, es necesario insertar actividades que busquen la empatía con estas tecnologías para reducir la ansiedad.

Palabras clave: Aprendizaje, Estrés y ansiedad, Sala virtuale.

1 Universidade Barriga Verde, Orleans - SC. *E-mail: aabretas@yahoo.com

2 Universidade Estadual do Maranhão, São Luís - MA. 


\section{INTRODUÇÃO}

Devido a pandemia do coronavírus, cerca de 2 bilhões de estudantes no mundo tiveram suas aulas suspensas na tentativa de reduzir o risco de contaminação pela COVID-19, no Brasil foram quase 55 milhões (UNESCO, 2020). Mesmo sem condições financeiras, muitos desses estudantes tiveram que adquirir utensílios tecnológicos para se adequar as aulas remotas. Outros, foram transferidos para casa de parentes na tentativa de suprir aquilo que Ihe era necessário. Em ambas situações o estudante teve sua estrutura emocional afetada. Cassel JC (1974), já preconizava que diante a calamidades, pessoas de baixa renda, são mais susceptíveis a estresse e ansiedade.

Educadores como Pietrukowicz MCLC (2001) enfatizam que dar apoio psicológico a esses estudantes é fundamental, diminuindo a possibilidade de efeitos deletérios a sua saúde, principalmente os emocionais. Esse momento de fomento e compulsão por aulas remotas em substituição às presenciais, é propício para gerar ansiedade, estresse e instigá-los as mais variadas angústias (KIERKEGAARD SA, 2010). Lembrando que esta etapa da vida estudantil, independente de aula remota, já imputa a dúvidas inerentes à sua existência seja vocacional, ético, acadêmico e/ou social, o que promove o estabelecimento de novos padrões de funcionamento do indivíduo para a transposição desta fase de transição (MATTA CMB, et al., 2017).

$O$ isolamento social decorrente da pandemia é uma condição que, por si só, já propícia o aparecimento de sintomas emocionais como alterações no apetite, no humor, fadiga física, sentimento de incompetência e, em casos extremos até depressão (BITTENCOURT RN, 2020). Além desses, outros sintomas podem aparecer como nervosismo, sentimentos de desamparo, vazio, solidão e tristeza que ao longo prazo, tornam-se gatilhos para o desenvolvimento de outras patologias ao humor deprimido e ansiedade (OVCHINNIKOV YV, et al., 2015). Muitos desses sintomas, como visto, são reverberados sobretudo nos estudantes.

Dados de pesquisas (CETIC, 2020), revelam que cerca de 97\% dos estudantes brasileiros acessam a internet via smartphone, sendo quase $20 \%$ por meio dos chamados planos pré-pagos. Uma condição que gera estresse ao estudante, pois acessar as salas virtuais consomem créditos podendo deixá-los sem conexão; além do fato de assistir aula pela tela do telefone não ser uma tarefa fácil. Mesmo aqueles estudantes abastados que conseguiram estruturar "tecnologicamente" seu ambiente domiciliar, ainda estariam susceptíveis às demandas/estressado ambiente virtual (SPALDING M, 2020). Boa parte desse desgaste estudantil foi decorrente da substituição abrupta do ensino presencial pelo remoto ou pelo híbrido.

Nesse sentido, pretende-se socializar informações sobre a reação dos estudantes universitários frente às tecnologias virtuais, que podem ocasionar diferentes reações/emoções. O objetivo do estudo foi a percepção estudantil em uma disciplina oferecida na Universidade Estadual do Maranhão, que foi ministrada na forma híbrida (2011) e na forma remota (2020). Em ambas as situações essas tecnologias e seus recursos como computador/internet, foram imprescindíveis para que os estudantes acessassem as salas de aula virtuais da referida disciplina.

\section{RELATO DE EXPERIÊNCIA}

Foi realizado um estudo de cunho qualitativo que adotou no processo investigativo, a coleta de dados por meio de conversas informais (percepções). O público-alvo foram os estudantes matriculados em uma disciplina presencial que é oferecida no final do curso universitário. Portanto, a "pressão" sobre elaboração de monografia e entrada no mercado de trabalho, já fazem parte da rotina emocional desses estudantes.

Além dessas "pressões" esses estudantes, tiveram que aprender a utilizar as tecnologias virtuais para acessar a sala virtual da disciplina. Sendo suas reações/emoções diante ao uso dessas salas relatadas neste estudo de caso. As referidas percepções foram obtidas somente no final da disciplina, evitando inibição ou receio de que seu comentário pudesse interferir na nota final.

Visando comparação de feedback foram usadas para o estudo duas turmas, da mesma disciplina, uma turma de estudantes matriculados no $2^{\circ}$ semestre de 2011 (agosto-dezembro) e outra turma no $1^{\circ}$ semestre de 2020 (março/julho). Embora esses estudantes de 2020, tenham iniciado a disciplina presencialmente nas duas primeiras semanas de março; devido à pandemia houve um recesso (abril-agosto), só retornando de forma virtual em setembro. 
Os estudantes matriculados na disciplina no ano de 2011desconheciam uma sala de aula virtual e o ensino híbrido. Situação semelhante daqueles de 2020, que desconheciam o que era ensino remoto; embora já tivessem noção de salas virtuais do sistema acadêmico (SigUema). A diferença foi que devido a pandemia os estudantes, de 2020, tiveram que aprender a usar essas salas de forma abrupta.

A premissa desse estudo foi: como esses estudantes de cursos presenciais reagiram emocionalmente diante às necessidades do uso de tecnologias virtuais em uma disciplina híbrida (2011) em uma remota (2020). A híbrida incorpora características tanto da sala tradicional quanto da virtual, enquanto a disciplina remota incorpora metodologias virtuais, sendo considerada como emergencial (TREVISANI FM e CORRÊA $Y, 2020$ ). Em ambos os casos, o professor usa sala virtual, sendo que na híbrida a sala é usada apenas como acessório, enquanto na remota como base exclusiva.

Nessa perspectiva do uso das salas virtuais, o estudante tem assumido controle em relação ao tempo, ao lugar e até do ritmo de seus estudos. Isso ocorre porque, ao usar a sala virtual, o estudante gerencia todo o processo e alternativas de aprendizagem (ANDRADE DPC e MONTEIRO MI, 2019). Podendo aprender, inclusive na ausência do professor; o que pode desencadear emoções negativas, caso não conclua seu aprendizado. E, devido às individualidades, essas emoções reverberam-se de forma diferente para cada estudante, podendo resultar em um total desgaste físico e mental; um burnout acadêmico (RICARDO YR e PANEQUE FRR, 2013).

De acordo com Mota IDD, et al. (2017), o termo síndrome de burnout é utilizado para designar aquilo que deixou de funcionar por exaustão decorrente da má adaptação do indivíduo a uma atividade estressante. Embora sentimento de frustração sejam manifestados, sua instalação acontece silenciosa sendo percebida somente quando afeta seu comportamento. Cabe aqui lembrar, que essa síndrome consta, desde 2019, na Classificação Internacional de Doenças emitida pela Organização Mundial da Saúde (WHO, 2018).

O alargamento desse conceito para atividades estudantis (pré-profissional) já vem sendo pesquisado, relatando que também ocorre em três dimensões: Exaustão emocional, Descrença e Ineficácia profissional. Pode começar durante o período acadêmico e prosseguir durante a vida laboral (MARTINEZIMM, et al., 2000). Daí reside a importância de estudos que visam perceber esses desgastes, pois podem servir como indicador tanto em nível de êxito acadêmico quanto profissional, possibilitando, se for o caso, de intervenções médicas preventivas.

\section{DISCUSSÃO}

A disciplina com carga horária de 60h é oferecida na forma presencial para dois cursos de Licenciatura de forma híbrida, desde 2011. Nessa época, era considerada como híbrida aquela disciplina presencial que utilizava $20 \%$ de sua carga horária de forma virtual (BRASIL, 2004). Depois de 2018, esse percentual aumentou, para 40\% (BRASIL, 2018). E, atualmente, de forma emergencial e temporária, deve ser usada $100 \%$ da carga horária, virtual (BRASIL, 2020).

Em 2011 a sala virtual da disciplina era acessada via Ambiente Virtual de Aprendizagem (AVA), uma ferramenta de gerenciamento do aprendizado, que para ter acesso adota-se uma plataforma possibilitando sua aplicação. Nesse caso a sala virtual era o AVA-Moodle, em que o MOODLE (Modular Object Oriented Dynamic Learning Environment) é um programa que faz a interação estudante $\leftrightarrow$ professor. Hoje 2020 a sala virtual ainda é acessada por um sistema (SigUema) por meio de software onde disponibiliza todas as disciplinas do curso.

As salas virtuais (2011 e 2020), além de serem um repositório de materiais e de vídeo aulas, contemplam ferramentas formativas como: Tarefa, onde o estudante pode enviar online as atividades; Questionário, testes direcionados, cujos resultados são fornecidos on time; Fórum, local para postar opiniões sobre o conteúdo; Chat, canal de comunicação imediata; Enquetes, perguntas para serem votadas entre os estudantes; Web, serviço de aulas/encontros virtuais ao vivo; e Glossário que inclui verbetes sobre determinado conteúdo. Para Moreira MA, et al. (2010), essas interfaces pedagógicas presentes nas salas virtuais são importantes no processo de aprendizagem dos estudantes. 
Foi percebido nos estudantes de 2011 e de 2020que além das dificuldades enfrentadas como falta de adaptação à plataforma: sala virtual e do SigUema, respectivamente; relatos sobre a fraca conexão de internet. Segundo eles deveriam ser consideradas tanto na aprendizagem, como imagem/som ruins prejudicando a qualidade das aulas, quanto no psicológico, como a dúvida se a aula ia "travar", afetando-os emocionalmente. Mesmo em 2011 cuja ação na sala virtual era apenas $20 \%$ os estudantes preferiam acessála na universidade, a grande maioria não tinha internet em casa. Os estudantes de 2020, não tiveram essa oportunidade, mesmo que a casa não fosse o melhor local, era única opção na quarentena.

É importante conseguir meios de reduzir a carga/pressão de estudos, para melhorar não apenas a eficácia do aprendizado, mas para torná-lo mais agradável e prazeroso. Uma diminuição do nível de estresse/ansiedade, tende a uma melhora no equilíbrio emocional do estudante e com isso, aumenta sua organização e eficácia do aprendizado (CABALLERO C, et al., 2007).

Embora em ambas as turmas, os estudantes relatassem sobrecarga de atividades virtuais; essa situação foi mais evidenciada em 2020, visto que estavam em total isolamento, ou seja, nas síncronas e assíncronas. Conforme Martins RXM (2020), as ferramentas síncronas são aquelas em tempo real onde professores e estudantes interagem ao vivo, afetando seu emocional. Um exemplo é o caso das Universidades Federais de Uberlândia e do Maranhão, onde $70 \%$ e $80 \%$ dos estudantes (www.comunica.ufu.br e www.portais.ufma.br, respectivamente) tiveram aumento de ansiedade devido ao ensino remoto.

Pelo fato dessa disciplina ser oferecida nos últimos períodos, boa parte dos estudantes de 2020 estava sobrecarregado e estressado emocionalmente. A explicação foi que concomitantemente estavam elaborando suas monografias. Diferente dos estudantes de 2011, as monografias de 2020 foram e apresentadas de forma remota; gerando mais "nervosismo". Lembrando que o fechamento da universidade devido a COID19 os estudantes não puderam concluir seus experimentos, prejudicando a elaboração de suas monografias.

Segundo esses estudantes em 2020, as apresentações online da defesa prévia, e da defesa propriamente dita, foram um dos momentos mais estressantes desse período remoto. $\mathrm{O}$ argumento foi o fato de ter uma plateia (virtual) externa, em alguns casos com mais de 100 pessoas, professores, colegas e familiares. Além daqueles (mesmos) desconfortos das aulas remotas: será que a internet vai cair? Será que vai faltar luz? Agregaram-se outros: quando será o melhor dia (sem barulho), qual o local da casa é mais adequado, dentre outros.

Pesquisadores como Vázquez PJC (2010) reforçam que todas essas dúvidas afetam fortemente nosso desempenho. Essa situação pode causar no estudante uma frustração acadêmica, daí reside o motivo de, nesse momento de ensino remoto, terem ocorrido muitos casos de abandono. De acordo com Matta CMB, et al. (2017), as dimensões pessoal e de estudo, são as de maior vulnerabilidade desses estudantes, requerendo um cuidado por parte da instituição, fornecendo-Ihes mais tempo de adaptação.

O uso compulsório das salas virtuais por ser, de certa forma, uma quebra de paradigmas, visto que os estudantes desconheciam por completo as diversas interfaces e ferramentas das salas virtuais, trouxe desconforto. Devido essa necessidade de interação virtual, ambas as turmas (2011 e, principalmente 2020) relataram transtornos como: $I$ ) ansiedade, pois queriam conhecer e dominar essas ferramentas tecnológicas; ii) desgaste, devido ao prazo (fixo) e formas de entrega das atividades e iii) estresse, pois os questionários e as avaliações, apresentavam cronômetro, limitando o tempo de realização.

Embora o relato geral dos estudantes (de 2011) quanto a importância de estudarem no formato híbrido, que o layout da sala virtual era atrativo e que as ferramentas pedagógicas (atividades) foram consideradas proveitosas, quando conversava individualmente percebia que o feedback era diferente. As reclamações eram inúmeras, desde que eram de cursos presenciais e que não iriam precisar da sala virtual; passando estresse pelo excesso de atividades, até a questão dos prazos de envio, segundo eles eram muito curtos. Já os estudantes de 2020 relataram que seu estresse e ansiedade decorriam de complicações dentro da sala virtual como baixar (Download) e anexar (UpLoad) vídeos e atividade, pois em ambas os casos requerem uma boa conexão de internet.

Outro entrave percebido e relatado, inclusive nos encontros presenciais, foi à concepção de que ao usarem a sala virtual, ficariam com labores (presencial e virtual). $O$ que foi modificado nas turmas seguintes pois 
perceberam que o ensino híbrido, além de incentivar a troca de experiências facilitava a busca pelo conhecimento via online, empoderando-os. Contudo, nem os professores que já adotavam ambientes online nas suas práticas, imaginavam que deveriam mudar de forma quase obrigatória, devido à expansão da Covid19 (MOREIRA JAM, 2020). Entretanto, sabendo da relevância da sala como repositório; ainda assim (para eles) o ensino híbrido deveria ser usado apenas de forma complementar, sem cobranças.

Outro descompasso do ensino remoto emergencial evidenciado em 2020 foi o fato que o professor deveria ministrar sua aula nos dias e horários respectivos de sua aula presencial. Muitas dessas aulas (lives) ficaram comprometidas devidas alguns estudantes não estarem mais disponíveis naquele, outrora, horário de aula. Como as disciplinas são semestrais e o $1^{\circ}$ período (março/julho) se prorrogou para setembro/novembro, era esperado que alguns estudantes tivessem agendados outros compromissos para esses meses.

Além das pressões no uso de tecnologias virtuais, tem-se o desconforto do isolamento decorrente do "não presencial" da falta de motivação por estar sozinho em frente a um computador (MORAN JM, 2011). Uma situação embora relatada por estudantes de 2011 e de 2020 foi mais reverberada naqueles de 2020 por causa do isolamento social. Muitos desses estudantes, por almoçarem no restaurante universitário, passavam praticamente o dia todo fora de suas casas; e ter que se habituar a uma sala de aula agora dentro de seu convívio familiar, foi uma das suas maiores dificuldades.

Essas situações por que passaram os estudantes, principalmente os de 2020, não pode ser "naturalizada" pela sociedade, como algo normal. Foi uma consequência do isolamento social da pandemia, que impactou aqueles indivíduos que atuavam em grandes grupos, como o caso do contato (próximo) entre os estudantes dentro de uma sala de aula. Porém, se as respostas desses estudantes para às tarefas virtuais, forem acompanhados de estafa, frustrações e irritabilidade. Caberá ao professor perceber cada situação e fazer adequações, conversando individualmente dando-Ihe autoconfiança.

Por fim, os estudantes estão submetidos a carga laboral igual a qualquer profissional, e, de certa forma, mantém uma relação de trabalho com sua instituição de ensino, que espera deles respostas sempre positivas no que diz respeito a sua "produção" acadêmica. Portanto, como preconizam Caballero C, et al. (2007), também estão submetidos a toda uma carga emocional decorrente dessas "pressões" cotidianas. Assim, face às antigas cobranças das aulas presenciais foram aguçadas agora com as aulas virtuais, condição propensa, inclusive, a síndrome de burnout.

Compreender à medida que as emoções estão interferindo no processo de aprendizagem dos estudantes, deve tentar modificar o que Ihe afeta. Essa situação de bem-estar faz com que estejam preparados; novas habilidades vão surgir e outras vão se renovar. Precisamos desencadear mecanismos de aprendizagem que gerem interações favoráveis na busca pelo conhecimento. É recomendado o uso prudente das ferramentas virtuais, principalmente quando usadas concomitantemente nos cursos presenciais, visto que esses estudantes tendem a refutá-las. Por isso precisa primeiro fomentá-los, requerendo sua empatia com essas tecnologias virtuais, para posterior uso e aplicação.

\section{REFERÊNCIAS}

1. ANDRADE DPC, MONTEIRO MI. Educação Híbrida: abordagens práticas no Brasil. Revista Eletrônica Científica Ensino Interdisciplinar, 2019; 5(14): 250-264.

2. BITTENCOURT RN. Pandemia, isolamento social e colapso global. Revista Espaço Acadêmico, 2020; 19(221):168178.

3. BRASIL. Ministério da Educação. Diário Oficial da União. Portaria 4.059. Dou 13/12/04, Seção 1, p.34. Brasília, 2004.

4. BRASIL. Ministério da Educação. Diário Oficial da União. Portaria № 1.428. Dou 28/12/18. Brasília, 2018.

5. BRASIL, Ministério da Educação.Diário Oficial da União.Medida Provisória 934. Dou 6/04/2020. Brasília, 2020.

6. CABALLERO C, et al. Relación del burnout y rendimiento académico com La satisfacción frente a losestudios. Avances PsicologíaLatinoamericana, 2007;25(2):98-111.

7. CASSEL JC. An epidemiological perspective of psychosocial factors in disease etiology. American Journal of Public Health, 1974; 64(11):1040-1043.

8. CETIC, Centro de Estudos Tecnológicos para Informação e Comunicação. Pesquisa revela que $97 \%$ dos estudantes brasileiros acessam a internet pelo smartphone. Disponível em: https://www.mobiletime.com.br/noticias, setembro de 2020.

9. KIERKEGAARD SA. Conceito de Anqústia. Editora Vozes: São Paulo, 2010.

10. MATTA CMB, et al. Adaptação, rendimento, evasão e vivências acadêmicas no Ensino Superior: Revisão da literatura. Psicologia Escolar e Educacional, 2017; 21(3): 583-591. 
11. MARTÍNEZ IMM, et al. (2000). Burnout em estudantes do ensino superior. Revista Portuguesa de Psicologia, 35:151 167.

12. MARTINS RXM.A COVID-19 e o fim da educação a distância: um ensaio. EmRede, 2020; 7(1):242-256.

13. MORAN JM. Modelos e avaliação do ensino superior a distância no Brasil. Educação Temática Digital, 2011;10(2):5470.

14. MOREIRA MA, et al. Buenasprácticas de aulas virtuales en la docencia universitária semipresencial. Rev.TESI,2010;11(1):425-445.

15. MOREIRA JAM, et al. Transitando de um ensino remoto emergencial para uma educação digital em rede, em tempos de pandemia. Dialogia, 2020;34:351-364.

16. MOTA IDD, et al. Síndrome de burnout em estudantes universitários: um olhar sobre as investigações. Motrivivência, 2017;29(1):243-256.

17. OVCHINNIKOV YV, et al. Burnout syndrome: diagnosis, principles of treatment, prophylaxis. VoennoMeditsinskiiZhurnal, 2015;336(7):17-24.

18. PIETRUKOWICZ MCLC. Apoio Social e Religião: uma forma de enfrentamento dos problemas de saúde. $2001.129 \mathrm{f}$. Dissertação (Mestrado) - Curso de Mestrado em Saúde Pública, Escola Nacional de Saúde Pública Sergio Arouca, Fundação Oswaldo Cruz, Rio de Janeiro, 2001.

19. RICARDO YR, PANEQUE, FRR. Burnout estudiantil universitário: conceptualización y estúdio. Salud Mental, 2013;36:337-345.

20. SPALDING M, et al. Desafios e possibilidades para o ensino superior: uma experiência brasileira em tempos de COVID-19. Research, Society and Development, 2020;9(8):1-23.

21. TREVISANI FM, CORRÊA Y. Ensino Híbrido e o desenvolvimento de competências gerais da Base Nacional Comum Curricular. Revista Prâksis, 2020;17(2):43-61.

22. UNESCO, Organização das Nações Unidas para Educação, Ciência e Cultura. Educação: da interrupção à recuperação. Disponível em: https://pt.unesco.org/covid19/educationresponse, setembro de 2020.

23. VAZQUEZ PJC. Diagnóstico de Síndrome de burnout en la comunidad académica de la Universidad de Vallarta. Revista Univallarta, 2010;8(3):103-111.

24. WHO World Health Organization, ICD11: International Classification of Diseases 11th Revision. Disponível em: www.who.int/classifications/icd/revision, setembro de 2020. 